\title{
CONSCIENTIZAÇÃO PÚBLICA SOBRE O CONSUMO DE ÁGUA: UMA ANÁLISE DA SITUAÇÃO EM RIO CLARO - SP VISANDO À PROPOSIÇÃO DE MEDIDAS DE CONSERVAÇÃO
}

\author{
M. S. RUIZ ${ }^{1}$, I. V. R. RUIZ ${ }^{2}$, I. K. RODRIGUES ${ }^{2}$, P. H. S. GUIMARÃES ${ }^{2}$, J. M. BERNARDELLI JUNIOR ${ }^{1}$, \\ ${ }^{1}$ Universidade Nove de Julho - Uninove, ${ }^{2}$ Colégio Koelle de Rio Claro - SP \\ maurosilvaruiz@uninove.br ${ }^{1}$
}

Submetido 28/11/2016 - Aceito 11/11/2017

DOI: $10.15628 /$ holos.2017.5403

\section{RESUMO}

As denúncias de desperdícios e vazamentos de água em Rio Claro dão indicações de falta de conscientização da população sobre a ameaça da falta d'água. O objetivo desse estudo foi diagnosticar a conscientização pública sobre o consumo de água em Rio Claro visando à proposição de medidas de conservação. A questão de pesquisa foi a seguinte: quais evidências indicam falta de conscientização da população rio-clarense sobre consumo de água em situação de estiagem prolongada? A metodologia utilizada envolveu a triangulação de informações obtidas via levantamento bibliográfico e documental, contatos com especialistas em recursos hídricos e de comunicação e marketing, e análise de postagens sobre desperdício de água no “Grupo Rio
Claro" do Facebook. Os principais resultados foram: (i) há preocupação, mas não conscientização da população sobre ameaça de escassez; e (ii) os materiais de divulgação sobre escassez são cartazes informativos, sem "apelo" de comunicação. A principal conclusão é que os cidadãos estão se sensibilizando sobre o problema, mas não dá para dizer que estejam se conscientizando. Recomenda-se campanhas massivas de educação ambiental, valendo-se de materiais de divulgação elaborados sob a ótica do Marketing Social, de modo a propiciar reflexão das pessoas sobre a ameaça de falta d'água.

PALAVRAS-CHAVE: Água, Desperdício, Conservação, Conscientização.

\section{PUBLIC AWARENESS OF WATER CONSUMPTION: AN ANALYSIS OF THE SITUATION IN RIO CLARO - SP IN ORDER TO PROPOSE CONSERVATION MEASURES}

\section{ABSTRACT}

Allegations of waste and water leaks in Rio Claro give indications of a lack of public awareness about the threat of water shortages. The aim of this study was to survey public awareness of water consumption in Rio Claro in order to propose conservation measures. The research question was: which evidences indicate a lack of awareness of rioclarense population about water consumption in the current scenario of prolonged drought? The methodology involved a triangulation of information obtained via bibliographical and documentary survey, contacts with water resource and communication / marketing experts, and information regarding waste of water posted in the "Rio Claro
\end{abstract}

Group" of Facebook. The main results were: (i) there are just evidences of concern, but not of effective public awareness about the threat of shortage; and (ii) the disclosure materials on shortages are focused only in informative posters without communication appeal. The main conclusion is that citizens are not totally aware of the problem of water shortage. It is recommended massive campaigns of environmental education, via promotional materials developed from the perspective of Social Marketing, in order to provide reflection of the population on the threat of water shortages.

KEYWORDS: Water, Waste, Conservation, Awareness. 


\section{INTRODUÇÃO}

A percepção dominante da água como um recurso infinito, auto-regenerável e com possibilidades ilimitadas de uso, induziu a população a utilizá-la sem o devido planejamento. A poluição, a proliferação de doenças e a sua escassez absoluta em várias partes do mundo evidenciam o equívoco dessa concepção e apontam para a necessidade de mudança visão quanto à importância desse recurso.

Há várias décadas Hardin (1968) ao analisar a exploração de recursos naturais classificados como bens de uso comum, introduziu o conceito de "Tragédia dos Comuns", constantemente lembrado em publicações sobre escassez decorrentes de uso sem mecanismos de controle. Este autor lembra que o crescimento populacional impõe pressão sobre os recursos naturais seja via o consumo excessivo ou via a degradação da qualidade, como ocorre com os recursos hídricos. Destaca que o consumo de bens como a água deve ser feito com consciência e moderação e ressalta que para sua proteção é necessário a criação de leis e o desenvolvimento de tecnologias para o tratamento dos poluentes.

Ostrom (1990) apresentou o conceito de "Governança dos Comuns" em contraponto à Tragédia dos Comuns, analisando várias situações locais de gestão de recursos naturais, visando conservação, a partir de interesses comuns dos próprios interessados (pessoas, comunidades, empresas etc.).

Embora nem todas as situações analisadas por Ostrom (1990) se mostraram bem sucedidas, a ideia da Governança dos Comuns atualmente é bem aceita na comunidade acadêmica e traz esperança de que se houver envolvimento de segmentos organizados da população na discussão da atual crise hídrica que assola o Sudeste Paulista, soluções consensuadas visando à conservação de água poderão emergir em anos vindouros. Essa ideia também fortalece o pressuposto de que as discussões e tomadas de decisão relativas à gestão de recursos hídricos não podem continuar ocorrendo principalmente na esfera política como vêm acontecendo.

O objetivo da pesquisa foi diagnosticar a conscientização pública sobre o consumo de água em Rio Claro visando à proposição de medidas de conservação.

A questão de pesquisa foi a seguinte: quais evidências indicam falta de conscientização da população rio-clarense sobre consumo de água em situação de estiagem prolongada?

\section{REVISÃO TEÓRICA}

\subsection{A água como bem de uso comum}

Ao longo da história da humanidade o homem sempre ocupou áreas próximas a rios em função da facilidade de acesso à água, obtenção de alimento (pesca), locomoção e fertilidade das terras para a agricultura nas planícies de inundação. À medida que as civilizações se desenvolveram outros usos emergiram como, por exemplo, a geração de energia e a navegação 
comercial dentre outros. Além disso, a água corrente passou também a ser cada vez mais utilizada como elemento receptor dos efluentes e dejetos gerados nas concentrações urbanas. Historicamente, havia uma concepção de que a água era um recurso infinito, com capacidade de auto-regeneração, e que, portanto, poderia ser usada sem preocupações de planejamento visando o seu uso no futuro. A degradação da qualidade deste recurso e a proliferação de doenças de veiculação hídrica em várias regiões do mundo foram apenas algumas das evidências de que a visão da humanidade a este respeito estava equivocada.

Hardin (1968) enfatiza que como a água é um bem de uso comum (pertence a todos), se for usada de forma indiscriminada, sem limites ou mecanismos de controle, pode resultar em situações que se aproximam da Tragédia dos Comuns1. Hardin (1968) acrescenta que como a população só tende a aumentar, todos querem ter mais, possuir mais, mas isso não é possível num mundo com recursos finitos, pois, desta forma, estes recursos tenderão a acabar. Ele acrescenta que a poluição também é consequência do crescimento populacional e função do lançamento dos dejetos e resíduos na água. A Política Nacional de Recursos Hídricos - PNRH (Lei n0 9433 de 1997) enfatiza que a água é um recurso finito passível de degradação ambiental podendo levar a situações de escassez.

Hardin (1968) destaca que ao usarmos ou consumirmos os bens de uso comum, a exemplo da água, devemos usar com consciência e moderação de modo a não degradá-los. Também destaca que a criação de leis é necessária para a proteção desses recursos contra a degradação, bem como desenvolver tecnologias para o tratamento dos poluentes ao invés de lança-los diretamente no meio ambiente.

A PNRH (Brasil, 1997) estabelece em um dos seus pressupostos que a água é um bem de uso comum de natureza finita, daí a necessidade de conservá-la. Sendo bem de uso comum, em tese, ela poderia ser apropriada por todos os cidadãos, de modo que não haveria interesse em sua conservação. É por esta razão que as leis e regulamentações, como a PNRH, por exemplo, são estabelecidas e sancionadas. Direitos e deveres dos cidadãos no que se refere ao aproveitamento dos recursos hídricos, incluindo extração, uso, reuso e/ou descarte da água são estabelecidos na PNRH.

A PNRH destaca no seu capítulo I, Art. 10, inciso IV que a gestão dos recursos hídricos deve sempre proporcionar o uso múltiplo das águas, enfatizando que em situações de escassez o uso prevalente será a dessedentação humana e animal.

\subsection{Bacias hidrográficas}

${ }^{1}$ A Tragédia dos Comuns é algo (um bem, por exemplo) que por ser de todos e para todos, começa a ser "dividido ilegalmente", ou seja, uns querem se aproveitar mais dele que outros. Hardin (1968) cita como exemplo o comportamento dos pastores no passado, que levavam cada vez mais animais para o pastoreio por não terem noção da finitude das pastagens. Este autor destaca que em situação de plena liberdade que os pastores tinham, eles continuavam incrementando seus rebanhos; caso isso seja feito em outras situações de bem de uso comum (como é o caso da água), situações de escassez podem ocorrer, pois vivemos num mundo finito. 
Uma bacia hidrográfica é o conjunto de terras drenadas por um rio e seus afluentes. Seu contorno é limitado pelas partes mais altas do relevo, chamadas de divisores de água. As águas das chuvas escoam superficialmente formando os riachos e rios ou infiltram no solo para a formação de nascentes e do lençol freático. Em condições naturais as cabeceiras são formadas por riachos que brotam em terrenos de maior declividade. À medida que as águas destes riachos descem, juntam-se com as águas de outros riachos. Estes pequenos rios continuam seus trajetos recebendo água de outros tributários, formando rios cada vez maiores até desembocar nos oceanos (Barrela, Petrere Jr, Smith, \& Montag, 2001).

Yassuda (1993) conceitua bacia hidrográfica como "o palco unitário de interação das águas como o meio físico, o meio biótico, e o meio econômico, social e cultural". Sob esta ótica, bacia hidrográfica permite uma abordagem integrada dos vários aspectos que interferem no uso dos recursos hídricos e na proteção ambiental. Do ponto de vista estritamente físico, uma bacia compreende a rede de drenagem situada entre os relevos mais altos dos entornos de uma região, denominados divisores de água (Barrela et al., 2001).

A PNRH definiu a bacia hidrográfica como a unidade territorial de gerenciamento dos recursos hídricos em substituição ao modelo tradicional, top-down, de gerenciamento pelas esferas de governo (federal, estadual e municipal) que prevaleceu por diversas décadasa no país. 0 objetivo foi promover a descentralização da gestão, saindo de uma estrutura centralizada e permitindo que a decisão seja tomada na bacia hidrográfica (Porto \& Porto, 2008).

Atualmente o gerenciamento dos recursos hídricos é descentralizado por bacias hidrográficas, tendo como atores envolvidos, representantes de órgãos dos diferentes níveis de governo (federal, estadual e municipal), dos usuários da água e das entidades não governamentais da sociedade civil. Nessas bacias prevê-se a implantação de comitês e agências de bacias para efetuarem o gerenciamento dos recursos oriundos da cobrança pelo uso da água (Malheiros, Prota, \& Rincón, 2013).

O atual sistema de gestão, que resulta de intensa mobilização de setores técnicos e organizações sociais, constitui um modelo democrático, descentralizado e participativo que permite equacionar conflitos pelo uso da água e todos os projetos que interferem nela, permitindo tomar decisões embasadas em planos de bacia (Mattes, Tagnin, \& Prata, 2014).

No Estado de São Paulo o gerenciamento dos recursos hídricos é descentralizado por unidades de gerenciamento (UGRHI), contemplando 22 unidades ao todo, como pode ser visto na Figura 1. 


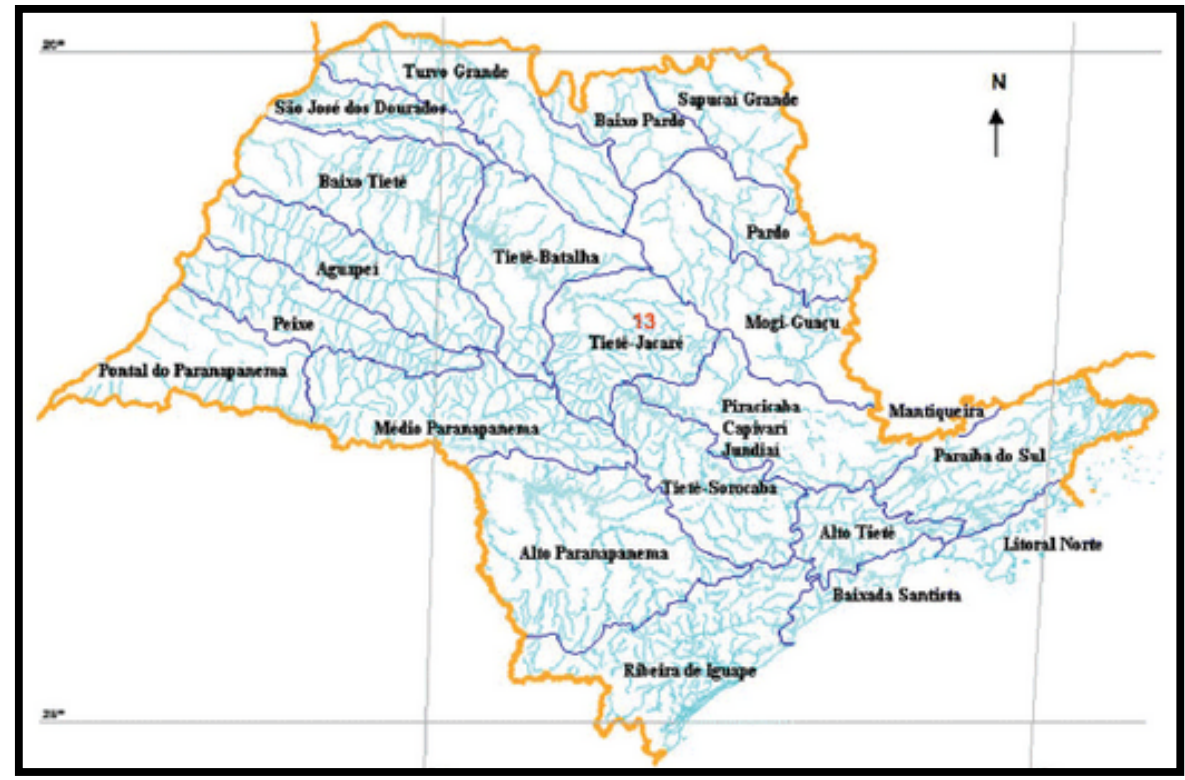

Figura 1: Unidades de gerenciamento (UGRHI) no Estado de São Paulo.

Fonte: Tundisi et al. (2008, p. 161)

As bacias hidrográficas se caracterizam pelos seus aspectos físicos, e pela influência do homem e dos grupos que nela se instalam. Os usos da bacia são determinados pelos grupos que a ocupam e sua interferência no meio físico ocorre em razão dos interesses desses grupos. Desta forma, as bacias sofrem modificações tanto pela ocupação humana, como por meios naturais (Bacci \& Pataca, 2008).

Numa bacia hidrográfica há a interação dos atores que nela habitam e/ou exercem suas atividades se apropriando da água para a satisfação de suas necessidades. Além disso, como os usos são concorrentes no seu território planejamento do uso da água e dos demais recursos (naturais e artificiais) nele existentes precisa ser feito tendo como referência os conceitos de gestão, conservação e sustentabilidade.

Pontuschka et. al. (2007) menciona que o conceito de bacia hidrográfica não se restringe somente ao rio principal e seus afluentes (tributários), trata-se de uma unidade territorial que registra tudo que ocorre nela, ou seja, a sua história. Nesta mesma linha, Porto; Porto (2008) destacam que é sobre o seu território que se desenvolvem as atividades humanas. Todas as áreas urbanas, industriais, agrícolas ou de preservação fazem parte de alguma bacia hidrográfica. Segundo eles é possível dizer que, no seu exutório, estarão representados todos os processos que fazem parte do seu sistema. Esses autores também acrescentam que o que ali ocorre é consequência das formas de ocupação do território e da utilização das águas que para ali convergem.

\subsection{As bacias hidrográficas dos rios Piracicaba, Capivari e Jundiaí, a reversão de água para a RMSP e o estresse hídrico do Sistema Cantareira}

As bacias dos rios PCJ situam-se na porção sudeste do Estado de São Paulo como mostra a Figura 2. O Rio Piracicaba nasce no Estado de Minas Gerais e desagua no Rio Tietê nas 
proximidades de Santa Maria da Serra.

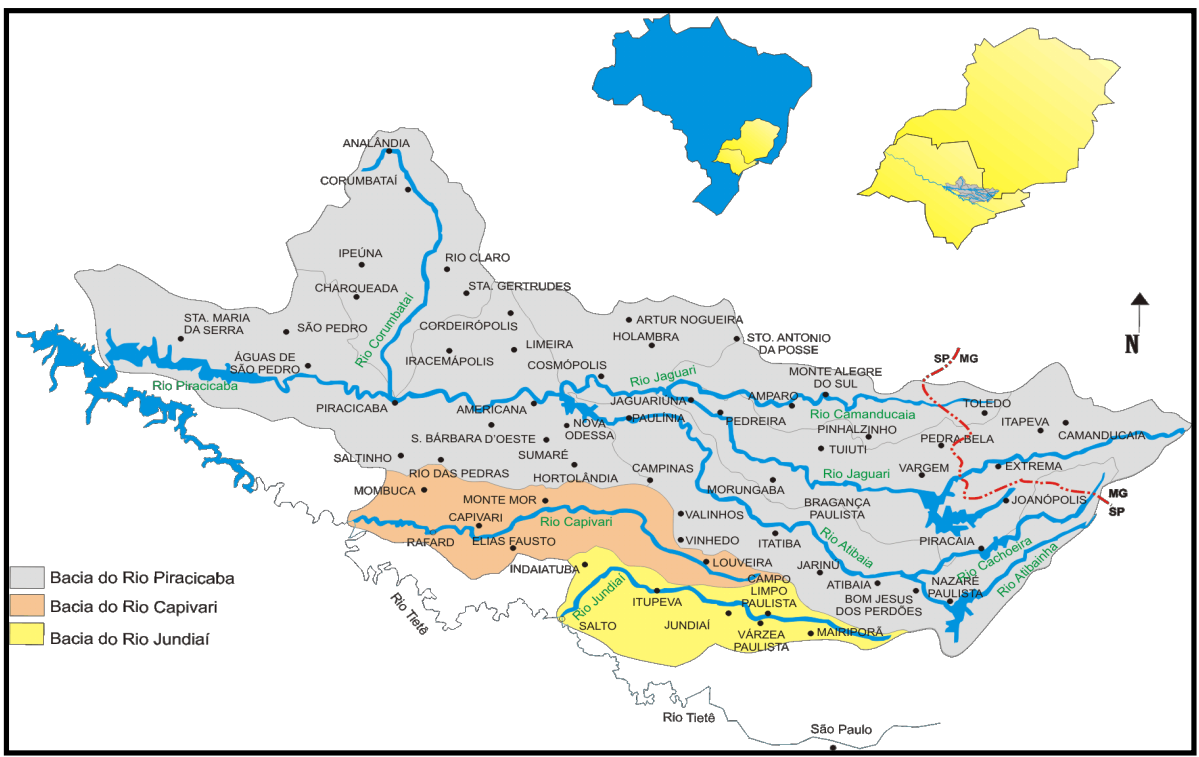

Figura 2: Bacias dos rios Piracicaba, Capivari e Jundiaí - PCJ.

Fonte: Rede Construção (2014).

As bacias dos rios PCJ situa-se numa área densamente povoada onde a água é utilizada intensamente em várias cidades para fins de abastecimento público e, também, nas zonas rurais, principalmente, em atividades relacionadas ao agronegócio. Parte da água produzida nessa bacia também é bombeada para uma das represas que compõe o Sistema Cantareira (Figura 3) que abastece bairros da capital paulista e de parte da Grande São Paulo.

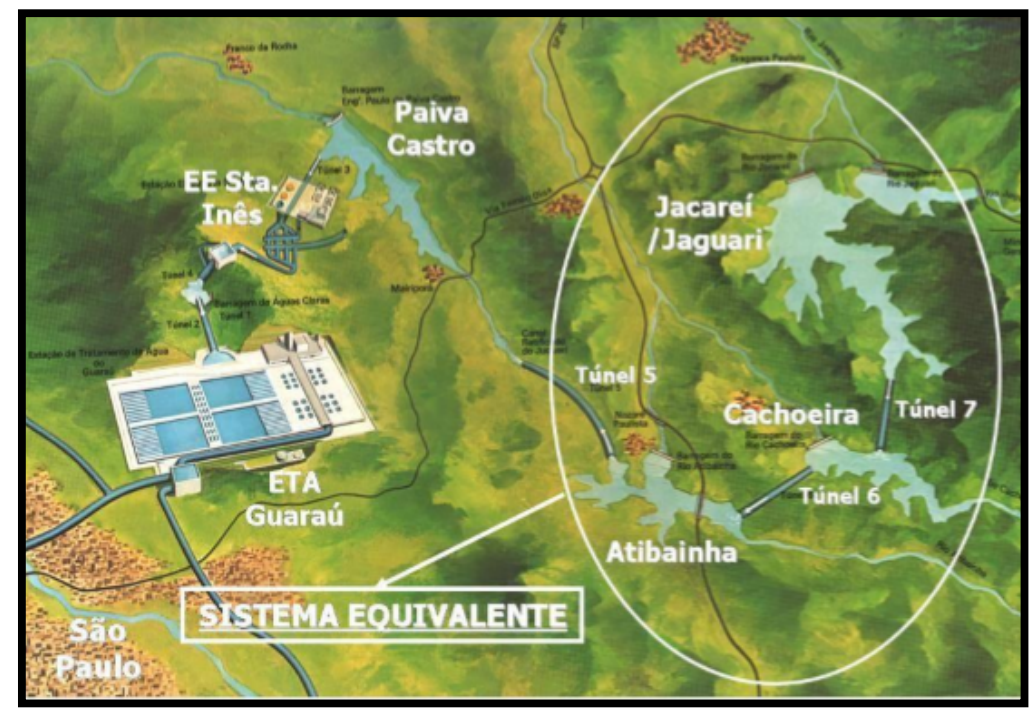

Figura 3: Sistema Cantareira.

Fonte: Agência Nacional de Águas [ANA], Departamento de Águas e Energia Elétrica [DAEE] (2013).

As cinco represas que compõem o Sistema Cantareira (Jaguari /Jacareí, Cachoeira, 
Atibainha, e Paiva Castro), representam hoje o centro das atenções para o desenvolvimento do Estado de São Paulo e do Brasil em função do estresse hídrico que está enfrentando. O sistema é responsável pelo abastecimento de 5 milhões de habitantes nas bacias dos rios PCJ e 9 milhões da Grande São Paulo, na bacia do Alto Tietê (Consórcio PCJ, 2013).

As normas em vigor até agosto de 2014 estipulavam os valores a serem revertidos para a RMSP em ordem de prioridade, sendo de prioridade primária a vazão de $24,8 \mathrm{~m}^{3} / \mathrm{s}$ e prioridade secundária a vazão de $6,2 \mathrm{~m}^{3} / \mathrm{s}$, o que totaliza a possibilidade de reversão de $31 \mathrm{~m}^{3} / \mathrm{s}$ para a RMSP. Para os Comitês das Bacias Hidrográficas dos Rios Piracicaba, Capivari e Jundiaí - Comitês PCJ, a vazão total de descarregamento foi estipulada em $5 \mathrm{~m}^{3} / \mathrm{s}$, sendo a vazão primária de $3 \mathrm{~m}^{3} / \mathrm{s}$ e secundária de $2 \mathrm{~m}^{3} / \mathrm{s}$ (ANA, \& DAEE, 2013).

Como decorrência da estiagem prolongada, as bacias dos rios PCJ também estão enfrentando estresse hídrico (Branco, 2014). Em meados de outubro de 2014, em função da intensificação do calor e dos efeitos da estiagem sobre o Rio Atibaia, a região de Campinas passou a praticar rodízio no abastecimento de água para 1,1 milhão de habitantes. As queixas de falta d'água se espalharam pelo município, em especial nas regiões mais altas e afastadas do centro (Leite \& Chapola, 2014).

Segundo Tundisi (2003), alguns pesquisadores atribuem a responsabilidade pela atual crise hídrica a um conjunto de problemas ambientais agravados com outros problemas relacionados à economia e ao desenvolvimento social. Dentre os principais fatores destacam: i) intensa urbanização, aumentando a demanda pela água; ii) infraestrutura pobre e em estado crítico; iii) problemas de estresse e escassez em razão de mudanças globais com eventos hidrológicos extremos aumentando a vulnerabilidade da população humana; e iv) problemas na falta de articulação e falta de ações consistentes na governabilidade de recursos hídricos e na sustentabilidade ambiental.

A Organização das Nações Unidas - ONU classifica regiões com mais de $20.000 \mathrm{~m}^{3} / \mathrm{hab} / \mathrm{ano}$ como áreas com grande abundância de água, e regiões com menos de $1.500 \mathrm{~m}^{3} / \mathrm{hab} /$ ano como áreas críticas quanto ao recurso (Rebouças, 2006). A região do PCJ insere-se nessas áreas críticas.

\section{METODOLOGIA}

O presente estudo quanto à sua abordagem é de natureza qualitativa e quanto aos objetivos pode ser vista como tanto de natureza com descritiva como exploratória.

A pesquisa qualitativa busca explicar o porquê das coisas, exprimindo o que convém ser feito, mas não quantifica os valores e as trocas simbólicas nem se submetem à prova de fatos, pois os dados analisados são não-métricos e se valem de diferentes abordagens. O desenvolvimento da pesquisa é imprevisível e o conhecimento do pesquisador é parcial e limitado (Gerhardt \& Silveira, 2009).

A pesquisa descritiva exige do investigador uma série de informações sobre o que deseja pesquisar. Esse tipo de estudo pretende descrever os fatos e fenômenos de determinada realidade (Triviños, 1987). 
Segundo Gil (2008) a pesquisa exploratória tem como objetivo proporcionar maior familiaridade com o problema, com vistas a torná-lo mais explícito ou elaborar hipóteses. Yin (2003) destaca que este tipo de pesquisa permite o desenvolvimento de linhas convergentes por meio de um processo de triangulação de informações de diferentes fontes de dados (YIN, 2003). A grande maioria dessas pesquisas, segundo Gil (2008), envolve: (a) levantamento bibliográfico; (b) entrevistas com pessoas que tiveram experiências práticas com o problema pesquisado; e (c) análise de exemplos que estimulem a compreensão.

Em relação aos procedimentos metodológicos adotados para atingir o objetivo proposto, foram realizadas as seguintes atividades:

a) Levantamento bibliográfico em artigos sobre recursos hídricos em revistas indexadas no Google Acadêmico e na base Scopus e, de dissertações e teses, no banco de teses e dissertações da Capes (Coordenação de Pessoal de Nível Superior).

b) Levantamento documental via relatórios, legislação sobre água, sites da internet, artigos de jornal e vídeos sobre gestão de recursos hídricos.

c) Levantamento de dados sobre consumo de água em Rio Claro junto ao DAAE via encaminhamento de dois ofícios ao diretor desse Departamento, um em 2014 e outro em 2016.

d) Seleção e análise de postagens de pessoas no "Grupo Rio Claro" do Facebook <https://www.facebook.com/groups/rioclarogrupo/?fref=ts> para avaliação da sensibilização e conscientização sobre o consumo de água na cidade.

e) Elaboração de planilhas e gráficos em Excel sobre as informações relativas a águas publicadas em jornais de Rio Claro, na EPTV - Regional e na TV Claret.

f) Realização de contatos com profissionais das áreas de comunicação e marketing para verificar as melhores formas de divulgação de informações e como devem ser elaborados os materiais para este fim de modo a sensibilizar e conscientizar a população.

Em seguida, procedeu-se a sistematização de todas informações e dados obtidos para possibilitar a análise via seus confrontos e cruzamentos e, por fim, a discussão dos resultados obtidos.

\section{ANÁLISE E DISCUSSÃO DOS RESULTADOS}

Este item está organizado em sete partes, quais sejam: captações de água de Rio Claro e efeitos da estiagem; legislação municipal aplicável à conservação de água; percepção pública sobre escassez; ações empresariais; o papel da mídia; atuação do Departamento Autônomo de Água e Esgoto - DAAE; e orientações de profissionais de comunicação e marketing para sensibilização e conscientização da população sobre conservação.

a) Captações de água de Rio Claro e efeitos da estiagem

Rio Claro situa-se na bacia hidrográfica do Rio Corumbataí que, por sua vez, localiza-se na 
porção Norte da bacia dos rios Piracicaba, Capivari e Jundiaí (PCJ).

As captações de água que abastecem a cidade são feitas pelo Departamento utônomo de Água e Esgoto (DAEE) no Rio Corumbataí e no seu afluente Ribeirão Claro. O Rio Corumbataí é responsável por cerca de $60 \%$ do abastecimento da população e o Ribeirão Claro é responsável pelos 40\% restantes (Departamento Autônomo de Água e Esgoto, 2014a).

De acordo com o Decreto no. $10.755 / 77$ e a Resolução Conama no. 357/05, esses dois corpos d'água inserem-se na classe II - águas destinadas ao consumo humano após tratamento convencional (Departamento Autônomo de Água e Esgoto, 2013).

Em visitas de campo e registros fotográficos realizados em outubro de 2014 observou-se redução de vazão nessas duas drenagens sendo possível observar a baixa profundidade da água nos leitos principais e comparar os níveis atuais com marcas nas bordas dos níveis de vazão normal.

Segundo o Departamento Autônomo de Água e Esgoto (2014a):

[...] o município de Rio Claro ainda não enfrenta problemas de racionamento ou restrições para o uso consciente da água. A área técnica deste Departamento tem implementado procedimentos operacionais visando otimização das captações de água de maneira que o sistema de abastecimento não seja afetado pela falta d'água. A continuidade da falta de chuva, no entanto, poderá resultar em dificuldades na captação, pois os níveis dos rios estão cerca de $40 \%$ abaixo da média para esta época do ano.

b) Legislação municipal aplicável à conservação de água

O Plano Diretor de Rio Claro (Lei Municipal no 3806) trata dos recursos hídricos no seu Capítulo IV, intitulado "Dos Recursos Hídricos". No Artigo 100 deste capítulo ele destaca a "Política Municipal de Recursos Hídricos" (Lei no 3499 de 16 de dezembro de 2004) que tem por base os seguintes fundamentos e objetivos:

I - A água é um bem de domínio público, limitado e de valor econômico;

II - O poder público e a sociedade, em todos os seus segmentos, são responsáveis pela preservação e conservação dos recursos hídricos;

III - A gestão dos recursos hídricos e do setor de saneamento básico será realizada com a participação do poder público e dos usuários e das comunidades, sob a responsabilidade da Administração Direta e Indireta do Município;

IV - Prioritariamente a água será utilizada para o abastecimento humano de forma racional e econômica;

V - A gestão municipal considerará a bacia hidrográfica como unidade de planejamento dos recursos hídricos;

VI - A gestão dos recursos hídricos será contemplada no Planejamento Urbano e Rural do Município;

VII - A titularidade do saneamento básico municipal é do Poder Público Municipal; 
VIII - A recuperação, preservação e conservação do regime dos corpos d'água localizados no município, em termos de quantidade e qualidade;

IX - A preservação da qualidade e o uso racional das águas superficiais e subterrâneas;

X - Proporcionar e aperfeiçoar o uso múltiplo com economia dos recursos hídricos, buscando o desenvolvimento da cidadania;

XI - A integração do município no sistema de gerenciamento das bacias hidrográficas dos rios $\mathrm{PCJ}$;

XII - A busca da universalização do acesso da população à água potável, e qualidade e quantidades satisfatórias;

XIII - A garantia do saneamento ambiental;

XIV - A promoção do desenvolvimento sustentável;

$X V$ - A instituição do efetivo controle social da gestão dos recursos hídricos, por parte de todos os segmentos da sociedade (Prefeitura do Município de Rio Claro, 2007, p. 35).

De modo geral, o que se percebe é que a Política Municipal de Recursos Hídricos reproduz os fundamentos e objetivos da Política Nacional e da Política Estadual de Recursos Hídricos, adaptando-os para o contexto do município. Segundo a referida política, a gestão dos recursos hídricos contempla a bacia hidrográfica como unidade de planejamento, os recursos hídricos devem ser considerados no planejamento urbano e rural do município, e prevê a integração do município no sistema de gerenciamento das bacias hidrográficas dos rios PCJ.

O Art. 101 da lei explicita que:

[...] o município estabelecerá diretrizes para usos sustentáveis para as bacias dos rios Cabeça e Passa Cinco, que deverão ser fontes de abastecimento de água para o divisor de águas Cabeça - Corumbataí. Em parágrafo único, enfatiza que deverão ser feitas gestões para que o trabalho seja articulado com a Prefeitura de Ipeúna, valorizando as áreas de proteção e recuperação dos mananciais junto aos Rios Cabeça e Passa Cinco (Prefeitura do Município de Rio Claro, 2007, p. 35).

Na Seção I, Art. 102, a Lei:

[...] institui a Programa de Recuperação de Cursos D'água e Fundos de Vale compreendendo um conjunto de ações, que promovam transformações urbanísticas estruturais e a progressiva valorização e melhoria da qualidade ambiental do município. No Art. 104 desta Seção, destaca que deverá ser implantado um plano emergencial de desassoreamento e recuperação ambiental das bacias do Ribeirão Claro, do Rio Cabeça e do Rio Corumbataí, visando garantia da qualidade do abastecimento de água no município integrado à criação dos respectivos parques municipais (Prefeitura do Município de Rio Claro, 2007, p. 36).

Em síntese, o Plano Diretor de Rio Claro contempla a preocupação com a conservação dos recursos hídricos e a sustentabilidade ambiental no município.

c) Percepção pública sobre escassez 
Como estudos de avaliação de percepção são difíceis de ser conduzidos, optou-se neste caso por fazer inferências de sensibilização e conscientização pública a partir de reduções nas estatísticas de consumo de água e análise de postagens sobre preocupações com a escassez no "Grupo Rio Claro" do Facebook.

A Tabela 1 mostra o consumo medido de água mês a mês em Rio Claro para 2013 e 2014 e as respectivas variações percentuais entre os mesmos meses de 2014 e 2013.

Tabela 1: Consumo de água medido mensalmente em rio claro em 2013, 2014 e 2015 e respectivas variações porcentuais para o mesmo mês em cada ano.

\begin{tabular}{|c|c|c|c|c|c|}
\hline \multirow{2}{*}{ Mês } & \multicolumn{2}{|c|}{ Consumo $\left(\mathrm{m}^{3}\right)$} & \multirow{2}{*}{$\begin{array}{c}\text { Variação } \\
\text { porcentual } \\
(\%)\end{array}$} & \multirow{2}{*}{$\begin{array}{c}\begin{array}{c}\text { Consumo } \\
\left(\mathrm{m}^{3}\right)\end{array} \\
2015\end{array}$} & \multirow{2}{*}{$\begin{array}{c}\text { Variação } \\
\text { porcentual } \\
\text { (\%) }\end{array}$} \\
\hline & 2013 & 2014 & & & \\
\hline Janeiro & 1065928 & 1185405 & $10,1 \%$ & 1044597 & $-13,5 \%$ \\
\hline Fevereiro & 988581 & 1228911 & $19,6 \%$ & 1037002 & $-18,5 \%$ \\
\hline Março & 1032130 & 1104639 & $6,6 \%$ & 966009 & $-14,4 \%$ \\
\hline Abril & 992328 & 1074192 & $7,6 \%$ & 961179 & $-11,8 \%$ \\
\hline Maio & 1025915 & 1015813 & $-1,0 \%$ & 948751 & $-7,1 \%$ \\
\hline Junho & 998618 & 966212 & $-3,4 \%$ & 952891 & $-1,4 \%$ \\
\hline Julho & 950012 & 972327 & $2,3 \%$ & 946962 & $-2,7 \%$ \\
\hline Agosto & 968517 & 949999 & $-1,9 \%$ & 964359 & $1,5 \%$ \\
\hline Setembro & 1059107 & 988438 & $-7,1 \%$ & 996522 & $0,8 \%$ \\
\hline Outubro & 1079871 & 1036516 & $-4,2 \%$ & 1034744 & $-0,2 \%$ \\
\hline Novembro & 1099238 & 1067348 & $-3,0 \%$ & 1299761 & $17,9 \%$ \\
\hline Dezembro & 1115699 & 1038334 & $-7,5 \%$ & 1011338 & $-2,7 \%$ \\
\hline
\end{tabular}

Fonte: Departamento Autônomo de Água e Esgoto (2014b; 2016).

Pela Tabela 1 percebe-se que a partir de maio de 2014 começou a haver uma redução no porcentual de consumo de água quando se compara os volumes consumidos nos mesmos meses de 2014 aos de 2013. A única exceção foi no mês de julho, muito provavelmente em função das férias escolares, quando o consumo de água nas residências tende a aumentar.

É interessante notar que a partir de maio de 2014 começou a haver disseminação diária de informações, pelos meios de comunicação, sobre a escassez hídrica no Estado de São Paulo. De junho a setembro de 2014 também dá para perceber uma tendência de redução de consumo, com algumas pequenas oscilações para cima em julho (mês de férias) e em setembro, provavelmente em função da elevação média da temperatura em relação aos três meses anteriores.

Quando se compara os dados de consumo mensal em 2015 relativamente a 2014, observase que foram registradas reduções porcentuais no período de janeiro a junho, com variações entre $-18,5 \%$ a $-1,4 \%$. Nos meses subsequentes, entre agosto e dezembro, foram observadas flutuações com aumentos e decréscimos dependendo do mês, muito provavelmente devido a variações na 
temperatura. Apenas no mês de novembro observou-se um aumento relativamente expressivo $(17,9 \%)$ no consumo de água no mesmo mês entre 2015 e 2014.

De modo geral, com base nos dados da Tabela 1, dá apenas para dizer que houve uma redução no consumo, de forma relativamente contínua, entre o período de maio e dezembro, quando se compara os dados de 2014 relativamente a 2013, em patamares que variaram entre $7,7 \%$ e $-1,0 \%$. Essa redução continuou de forma mais acentuada, no período de janeiro a julho quando se compara os dados de consumo de 2015 relativamente aos de 2014, em patamares que variaram de $-18,5 \%$ a $-1,4 \%$. É possível que um dos fatores que possa ter contribuído para a redução do consumo nesses dois períodos tenha sido uma melhoria no nível de conscientização da população sobre o problema da escassez, em nível regional, porém, esta afirmação deve ser feita com muita reserva, pois os dados disponíveis não permitem dizer isso de forma categórica.

Em relação às postagens no "Grupo Rio Claro" (Facebook, 2014), foi possível perceber que algumas pessoas:

- têm consciência de que a água é um bem de uso comum e que precisa ser usada de forma racional;

- percebem a necessidade de sensibilização e conscientização para o uso racional da água;

- elogiam quem está postando matérias sobre conservação de água, pois reconhecem que esta é uma forma de conscientizar as pessoas;

- têm alguma noção de sustentabilidade e, portanto, da necessidade de usar a água racionalmente no presente para permitir o acesso das futuras gerações a este recurso;

- reconhecem a necessidade de campanhas educativas por parte das autoridades visando à sensibilização e conscientização da população;

- entendem que pessoas que usam este recurso indiscriminadamente, por exemplo, para lavagem de calçadas, em situação de escassez, devem ser denunciadas e multadas, porém, não têm ideia de como e onde denunciá-las;

- julgam que podem usar a água da forma que quiserem pelo fato pagarem suas contas referentes aos consumos mensais;

- acham que a falta de bom senso do público em relação ao consumo de água é generalizado e que a conscientização somente ocorrerá quando a água de fato acabar;

- acham que a adoção de cobrança de água de forma escalonada, por patamares de consumo (em "L"), poderá reduzir o desperdício;

- percebem e registram casos de vazamentos (na rede, em reservatórios) ou de má gestão dos serviços relacionados à água;

- mencionam que não há um sistema eficiente de captação, armazenamento e distribuição de água no município. 


\section{d) Ações empresariais}

A Whirlpool, que fabrica máquinas de lavar em Rio Claro e utiliza uma grande quantidade de água nos testes desses produtos, disponibiliza as seguintes informações no seu site sobre redução de consumo:

"As iniciativas para diminuição do consumo de água na Whirlpool proporcionaram uma economia de mais de $8,5 \mathrm{mil} \mathrm{m}^{3}$ em 2012. Foram implementados diversos projetos, com ênfase em captação e uso da água de chuva e no reuso de água tratada. Em todas as unidades o consumo de água por produto produzido ficou abaixo das metas fixadas para o ano, com exceção da unidade São Paulo, cujo desempenho ficou 11\% acima da meta devido ao novo processo de testes de purificadores de água. Inaugurada em julho, a Estação de Tratamento de Efluentes do Centro de Tecnologia de Lavanderia, na unidade Rio Claro, representou uma contribuição importante para a economia de água obtida pela companhia em 2012. A relevância relaciona-se ao grande consumo de água deste centro de tecnologia que tem mais de 300 postos de testes de produtos de lavanderia. O projeto - homenageado com Menção Honrosa no 8 Prêmio Fiesp de Conservação e Reuso da Água - proporcionou a redução em $60 \%$ do volume de água captada em poços artesianos, e deixou de descartar 3,96 milhões de litros/mês de efluentes - mais de $90 \%$ da carga, sendo que 2,6 milhões de litros, em valores estimados, são reutilizados nos testes de laboratório e 1,4 milhão em outras atividades, como sanitários e lavagem de piso. Em 2012, 2,6 milhões de litros de água deixaram de ser captados a cada mês" (Whirlpool, 2012).

Embora a mensagem divulgada no site tenha uma conotação forte de marketing, para reforçar a imagem da empresa como ambientalmente correta, as suas ações em economia de água são importantes em função de se tratar de uma grande empresa que utiliza volumes significativos na etapa final do seu processo produtivo.

O Supermercado Enxuto, através do seu programa Enxuto Sustentabilidade, de forma muito simples, tenta sensibilizar os clientes sobre a necessidade do uso racional da água via a afixação de cartaz chamando a atenção para formas de uso consciente.

Em seu cartaz há os seguintes dizeres:

“Estamos vivendo um momento de racionamento de água em várias cidades do Estado de São Paulo. Portanto, utilize-a de forma consciente!

- Não lave quintais, calçadas, carros ou motos com a mangueira;

- Use a máquina de lavar roupas na capacidade máxima;

- Mantenha a torneira fechada enquanto escova os dentes ou se ensaboa no banho;

- Também feche a torneira para ensaboar as louças;

- Reutilize a água sempre que possível”.

Outra iniciativa que indiretamente tem efeito positivo na conservação de água refere-se à coleta de óleo de cozinha usado em ecopontos instalados em supermercados (Enxuto e Covabra) e no Shopping Center da cidade. Nesses locais, estão instaladas bombonas onde são depositadas embalagens plásticas contendo o óleo usado. O seu recolhimento para reutilização reduz o descarte inadequado nas pias das cozinhas e, consequentemente, as despesas com limpeza em 
caixas de gordura, os custos de manutenção de redes de esgotos e os custos com o tratamento da água (Bióleo, 2014).

Em síntese, percebe-se que algumas empresas instaladas em Rio Claro têm ações de consumo sustentável de água e outras estão engajadas em ações de disseminação de informações e/ou de comprometidas com ações de conservação.

\section{e) O papel da mídia}

A mídia escrita e falada tem desempenhado um papel interessante na veiculação de informações sobre escassez de água em função da crise hídrica paulista.

Pela Figura 4 observa-se que as palavras-chave que melhor refletem o conteúdo das matérias veiculadas no Jornal Cidade de Rio Claro também são escassez (63\%) e conservação (27\%).

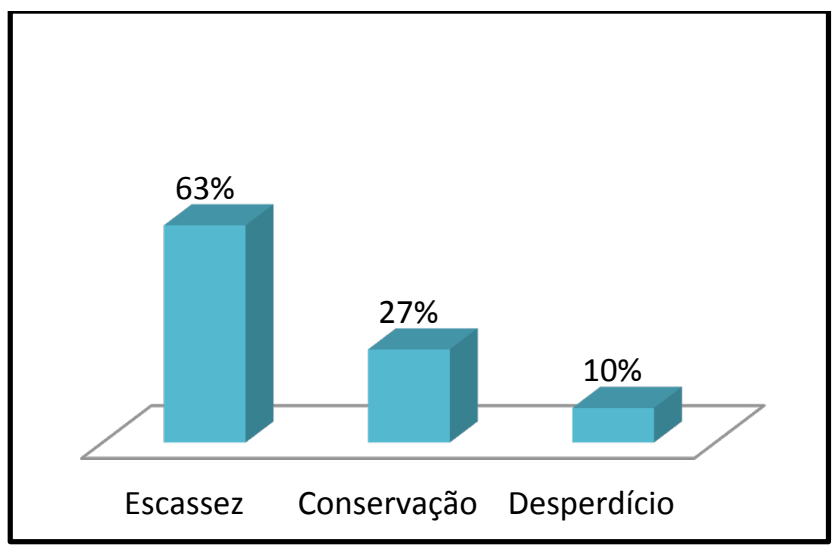

Figura 4: Distribuição porcentual das classificações das matérias sobre água publicadas no Jornal Cidade de Rio Claro. Fonte: Jornal Cidade (2014).

As quantidades de matérias sobre água apresentadas pelas redes de TVs local (TV Claret) e regional (EPTV) são bem inferiores às veiculadas na mídia escrita. A TV Claret divulgou 11 matérias enquanto a EPTV apenas 5 (Globo. Com, 2014; TV Claret, 2014).

Uma forma de disponibilização de informação que tem chamado atenção principalmente do público jovem é um rap apresentado na EPTV que diz:

"E comece a mudança na sua casa. Porque o que hoje vaza, amanhã com certeza fará falta Água Potável, é tesouro, então trate bem seu ouro. Faz bem para o planeta e para o bolso Economize água, não perca esse gol (Porque água é vida). Juntos vamos vencer (Precisamos reaprender). Contamos com você (O desperdício é o grande vilão). Economize água, não perca esse gol (É hora de se ligar). Juntos vamos vencer (Se souber usar, nunca vai faltar)" (Rede Globo, 2014).

A veiculação de informações enfatizando escassez, conservação e desperdício têm ocorrido em Rio Claro, porém, percebe-se que somente isso não é suficiente para a sensibilização e conscientização da população.

f) Atuação do DAAE

Após a captação da água, o DAAE efetua o bombeamento por meio das estações elevatórias 
e adutoras até as duas estações de tratamento, onde ela é submetida a processos físico-químicos (adsorção, coagulação, floculação, decantação, filtração, desinfecção e fluoretação) para tratamento, de acordo com a legislação vigente (Departamento Autônomo de Água e Esgoto, 2013).

Segundo o Departamento Autônomo de Água e Esgoto (2014a):

"[...] o município de Rio Claro ainda não enfrenta problemas de racionamento ou restrições para o uso consciente da água. O Departamento vem implementando procedimentos operacionais visando a otimização das captações de água para que o sistema de abastecimento não seja afetado pela falta de água. A continuidade da falta de chuva, no entanto, poderá resultar em dificuldades de captação, pois os níveis dos rios estão cerca de $40 \%$ abaixo da média para esta época do ano (2014). Nenhuma medida emergencial foi necessária até agora. A conscientização da população quanto ao uso racional da água é fundamental para se evitar medidas técnicas que poderão ser tomadas, caso sejam necessárias, para minimizar os transtornos à comunidade se houver agravamento no quadro do abastecimento. A orientação é para que as pessoas evitem o máximo possível o desperdício de água. O uso consciente é fundamental para que o município mantenha a captação em níveis satisfatórios para o tratamento, reservação e distribuição de água tratada".

Segundo Silva (2013):

“[...] a taxa de desperdício de água em Rio Claro é de 35\%, menor que o índice nacional, que varia entre $37 \%$ e $42 \%$. De acordo com o DAAE, no contexto do programa de redução de perdas de água, o município tem investido na substituição das comportas das estações de tratamento de água, na correção de vazamentos diversos nas tubulações das estações de tratamento e reservatórios, e na substituição de redes de abastecimento e de 19 mil hidrômetros. No entanto, a população também precisa colaborar, utilizando água de forma consciente. O DAAE contribui para a conscientização popular realizando ações que incentivam o uso racional da água. Essas ações são palestras e visitas monitoradas de estudantes às estações de tratamento. O objetivo é dar a eles a oportunidade de conhecer todo o processo, desde a captação até a chegada da água nas residências, bem como sensibilizar os jovens sobre as questões de escassez do líquido potável e a sua preservação". (...) Ainda segundo o DAAE, além de evitar o desperdício, a população também pode ajudar não fazendo descarte incorreto do lixo, principalmente às margens dos rios. A poluição das águas por diferentes substâncias e o descarte irregular de lixo podem comprometer a quantidade de água, através do processo de assoreamento dos rios e a qualidade da água bruta captada para processo de tratamento nas estações".

Mesmo enfrentando limitações típicas de órgãos públicos, o DAAE vem desempenhando ações de educação ambiental, porém, sem resultados expressivos, provavelmente em função da forma como conduz tais ações.

g) Orientações de profissionais de comunicação e marketing para sensibilização $e$ conscientização da população

Os recursos visuais, segundo um comunicólogo contatado:

[...] precisam ter apelo visual; pode ser, por exemplo, uma imagem chamativa que impacta 
as pessoas no primeiro olhar. Os textos dos materiais educativos a serem utilizados não devem ser muito informativos, mas precisam propor uma reflexão sobre o problema. É importante aliar uma boa fotografia a um texto refletivo, de modo a promover impacto, da mesma forma como os profissionais de comunicação abordam questões polêmicas. No caso em questão, poder-se-ia inserir uma frase ou texto curto que pudesse reforçar a escassez da água e, a partir daí, produzir diferentes "cartazetes" ou imagens para cada aspecto deste tema. A ideia pode passar por uma ação de produzir algumas imagens e distribuir pelas mídias eletrônicas e redes sociais como Facebook, Twiter, Whatsapp. É importante também focar no público jovem que acessa frequentemente a internet, o que dá um direcionamento de linguagem para os cartazetes" (Ribeiro, 2014).

Opinando sobre as considerações do comunicólogo, dois profissionais da área de marketing fizeram os seguintes comentários:

Profissional 1:

“[...] o colega está corretíssimo! Ações desta natureza precisam ser impactantes, pois precisam ter em perspectiva mudanças de atitude e comportamento. Não dá para ser complacente ou fingir que o assunto é mais ou menos sério. A abordagem que precisa ser usada é a do Marketing Social, não a do Marketing Comercial" (Gabriel, 2014).

Profissional 2:

"Quando falamos sobre recursos hídricos, estamos nos referindo aos problemas já existentes, às previsões e prognósticos científicos e, também, sobre situações que possivelmente enfrentaremos em um futuro não muito distante. Ou seja, estamos falamos de um problema da humanidade, de uma dimensão que a maioria das pessoas nem é capaz de imaginar. Quaisquer que sejam os materiais com o objetivo de alertar sobre os problemas relacionados a essa questão, sejam eles os mais básicos do dia-a-dia, ou os mais complexos que envolvem cidades, estados, nações, organizações mundiais, etc., devem ser carregados de uma mensagem alarmante. Sinceramente creio que, de alguma forma, elas devem seguir a ideia da estratégia usada nos maços de cigarro. Acredito que estamos diante de uma situação que demanda uma estratégia com alguns pontos cruciais: senso de urgência; senso catastrófico (dentro da realidade, usando a verdade); overexposure (transporte público, TV, escolas, mídia de massa, etc.); estratégia com as escolas (não apenas cartazes, mas um programa interativo); tecnologia (talvez via utilização de algum aplicativo que pudesse ser compartilhado nas escolas) ajudando a salvar algo ou alguma coisa. Doe seu lanche :) simbolicamente, algo nessa linha.... muita coisa pra molecada pensar. (...) Se eu fosse montar um material, eu buscaria uma discussão interessante, com a cultura de rua, com um grafiteiro conhecido, um que tivesse uma boa carga cultural. Estes colegas têm uma sensibilidade incrível sobre os desafios da humanidade. Poder-se-ia, dessa forma, criar uma linha de material usando grafite. Como se fosse material para colocar nas paredes de rua. Em São Paulo e no Rio de Janeiro têm grafiteiros fantásticos. É só buscar contato com alguns e ver quem toparia participar do trabalho. Geralmente, essas pessoas são sensíveis para fazer algo de graça quando se trata desse tipo de atividade" (Trindade, 2014). 


\section{CONSIDERAÇÕES FINAIS}

Algumas considerações específicas que podem ser feitas a partir dos resultados deste estudo são:

- A água é um bem de uso comum, ou seja, pertence a um indivíduo, mas também pertence a toda a população. Em função desta condição, não é fácil para as pessoas se posicionarem com clareza e imparcialidade em situações que envolvem desperdício;

- Percebe-se que atualmente são poucas as medidas voltadas à sensibilização e conscientização da população sobre o estado atual de escassez de recursos hídricos em Rio Claro e região. Essas medidas são "tímidas" e localizadas, via cartazes em supermercados, nem sempre bem elaborados de modo a chamar a atenção do público;

- Pela ligeira redução de consumo observada quando se compara os consumos medidos pelo DAAE de Rio Claro para os meses no período de maio a setembro entre 2014 e 2013 (Tabela 1), aparentemente tem havido certo nível de conscientização da população, provavelmente em parte sensibilizada pelas informações diárias disseminadas pelos meios de comunicação sobre a crise hídrica paulista;

- Nas postagens registradas no "Grupo Rio Claro" não se observou nenhuma menção à utilização de água de reuso, embora a mídia tenha dado destaque a soluções criativas de cidadãos principalmente no reaproveitamento da água utilizada nas máquinas de lavar roupa.

Como considerações mais gerais, dá para dizer que segmentos da população, com maior acesso aos meios de comunicação, parecem estar preocupados com a ameaça de escassez em função das informações veiculadas pela mídia, mas não dá para dizer que há conscientização de fato. A partir de maio de 2014 até dezembro deste ano, percebe-se uma ligeira tendência de redução de consumo de água comparativamente aos mesmos meses de 2013, situação que perdura no período de janeiro a julho de 2015 comparativamente a 2014. Entretanto, a partir da simples análise desses dados sem suporte de uma pesquisa de opinião e de outros fatores (climáticos, por exemplo) que podem ter interferido na redução do consumo, não é possível dizer que essas reduções se devem à maior conscientização da população sobre a escassez deste insumo. Pode-se dizer apenas que pode ter sido um dos fatores que eventualmente contribuiu com a redução.

Em relação à utilização de água pelos rio-clarenses, na condição de estiagem atual, as opiniões no Facebook transitam entre dois extremos: a necessidade de adoção de medidas punitivas (multas para o uso não sustentável do recurso) e uso à vontade uma vez que quem paga a conta é o usuário. A atual "avalanche" de informação sobre a crise da água, aparentemente pouco informa, pois quando os cidadãos se referem à aplicação de multa aos usuários pouco conscientes, eles mencionam que não têm ideia do valor que vem sendo aplicado 
por alguns municípios e nem de qual órgão público seria a atribuição de aplicá-la.

A preocupação com a conservação de água, a sustentabilidade na utilização dos recursos hídricos e a garantia de abastecimento da população estão presentes no texto do Plano Diretor Municipal.

Percebeu-se também que os materiais de divulgação existentes sobre a escassez de água atual são "tímidos", se limitando a cartazes informativos, porém sem "apelo" de comunicação.

A principal conclusão do estudo é que a conscientização da população deverá ser feita via campanhas massivas de educação ambiental, envolvendo a mídia, universidades e ONGs, valendo-se de materiais de divulgação que precisam ser elaborados por profissionais especializados. O foco dessas campanhas deve ser no uso racional da água enfatizando o combate ao desperdício, o reuso, a utilização de aparelhos sanitários economizadores de água e a orientação da população para a detecção e controle de perdas. Medidas de incentivo econômico, via premiações (bônus para quem consumir menos) e medidas punitivas (fiscalização e multas), para usos indiscriminados (lavagens de calçada várias vezes por semana) também precisam ser enfatizadas.

Para que essas campanhas tenham efetividade prática, considera-se de fundamental importância a utilização de recursos visuais criativos como, por exemplo, folhetos, folders educativos e outdoors elaborados por equipes interdisciplinares envolvendo psicólogos, sociólogos, comunicólogos e profissionais da área técnica, para que as mensagens visuais sejam disseminadas de forma a sensibilizar a população.

\section{AGRADECIMENTOS}

Os autores agradecem ao prof. Gunar Koelle, do Colégio Koelle de Rio Claro, ao Departamento Autônomo de Água e Esgoto (DAAE) e, especialmente, à profa. Edna Gubitoso pelo apoio na revisão e formatação final do artigo.

\section{REFERÊNCIAS}

Agência Nacional de Águas; Departamento de Águas e Energia Elétrica. (2013). Dados de referência acerca da outorga do Sistema Cantareira. Brasília: Autores.

Bacci, D. L. C., \& Pataca, E. M. (2008). Educação para a água. Revista de Estudos Avançados, 22(63), 211-226.

Barrela, W., Petrere Jr, M., Smith, W. S., \& Montag. L. F. A. (2001). As relações entre as matas ciliares, os rios e os peixes. In: Rodrigues, R. R.; Leitão Filho, H. F. (Orgs.). Matas Ciliares: conservação e recuperação (pp. 187-200). São Paulo: Edusp.

Bióleo. (2014). Consulta geral a home page. Recuperado em 24 setembro, 2014, de http://bioleo.org.br 
Branco, M. (2014, maio 5). Situação do Sistema Cantareira é sensível, diz Izabella Teixeira. $\begin{array}{llllll}\text { Agência } & \text { Brasil. } & \text { Recuperado } & 25 & \text { junho, }\end{array}$ http://agenciabrasil.ebc.com.br/geral/noticia/2014-05/para-izabella-teixeira-situacao-dosistema-cantareira-e-sensivel

Brasil. (1997). Lei no 9.433, de 8 de janeiro de 1997. Institui a Política Nacional de Recursos Hídricos, cria o Sistema Nacional de Gerenciamento de Recursos Hídricos, regulamenta o inciso XIX do art. 21 da Constituição Federal, e altera o art. 10 da Lei ํo 8.001, de 13 de março de 1990, que modificou a Lei no 7.990, de 28 de dezembro de 1989. Diário Oficial da União, Brasília, DF.

Consórcio PCJ. @013). Ofício SE 238/2013. Encaminhamento de contribuições à revisão da outorga do Sistema Cantareira, Americana. 11 out.

Departamento Autônomo de Água e Esgoto. (2013). Relatório Anual de qualidade de água. Rio Claro: DAEE. (folheto).

Departamento Autônomo de Água e Esgoto. (2014a). DAAE alerta para o consumo de água. $\begin{array}{llll}\text { Recuperado em } 21 \text { setembro, de } & \text { 2013, }\end{array}$ http://www.daaerioclaro.sp.gov.br/pagina.geral.php?pagina=Daae\%20alerta\%20para\%200\% 20consumo\%20\%20consciente\%20da\%20\%C3\%A1gua

Departamento Autônomo de Água e Esgoto. (2014b ). Consumo de água medido pelo DAEE no período de janeiro de 2009 a setembro de 2014. Rio Claro: DAEE. (Oficio recebido).

Departamento Autônomo de Água e Esgoto. (2016). Processo Administrativo DAAE $n$. 000012/2016 - Planilha Consumo. Rio Claro: DAEE. (Oficio Tributação n. 04/2016 recebido).

Facebook. (2014). Grupo "Febrace 2015" - Pesquisa sobre água (Período de 11 maio - 30 setembro). Recuperado em 30 setembro, 2014, de https://www.facebook.com/groups/269833276531752/?fref=ts

Gabriel, M. L. D. S. (2014). Sugestões para elaboração de material informativo sobre escassez hídrica. Recuperado em 29 outubro, 2014 de mgabriel.br@gmail.com

Gerhardt, T. E., \& Silveira, D. J. T. (2009). Métodos de pesquisa. Porto Alegre: UFRGS Editora.

GIL, A. C. (2008).Métodos e técnicas de pesquisa social. (6a ed.). São Paulo: Atlas.

Globo.Com. (2014). Pesquisa sobre água (Período de 11 de maio a 30 setembro). Recuperado em $30 \quad$ setembro, 2014, de http://redeglobo.globo.com/busca/?q=\%C3\%A1gua\&cat=b\&ss=5cf81f64bad08190\&st=rede globo\&page $=9$

Hardin, G. (1968). Tragedy of Commons. Science, New Series, 162(3859), 1243-1248.

Jornal Cidade (2014). Pesquisa sobre água (Período de 11 de maio a 30 setembro). Recuperado em 30 setembro, 2014 de http://www.jornalcidade.net/pesquisar-noticias/ 
Leite, F., \& Chapola, R. (2004, outubro 15). Sabesp ignora ordem e libera menos água para Campinas. O Estado de São Paulo.

Malheiros, T. F., Prota, M. G., \& Rincón, M. A. P. (2013). Participação comunitária e implementação dos instrumentos de gestão da água em bacias hidrográficas. Revista Ambiente \& Água, 8(11), 98-118.

Mattes, D., Tagnin, R., \& Prata, J. (2013). A crise é maior do que a chuva. Recuperado em 13 outubro, 2013, de http://www.diplomatique.org.br/artigo.php?id=1638

Ostrom, E. (1990). Governing the commons: the evolution of institutions for collective action. Cambridge: Cambridge University Press.

Pontuschka, N. N. et al. (2007). Para ensinar e aprender geografia (Coleção Docência em Formação. Série Ensino Fundamental). São Paulo: Cortez.

Porto, M. F. A, \& Porto, R. L. L. (2008). Gestão de bacias hidrográficas. Estudos Avançados, 22(63), 43-60.

Prefeitura do Município de Rio Claro (2007). Lei n. 3806, de 28 de dezembro de 2007. Dispõe sobre a revisão do plano diretor do município de Rio Claro. Diário Oficial da Cidade de Rio Claro, pp. 34-36.

Rebouças, A. C. (2006). Água doce no mundo e no Brasil. In: Rebouças, A., Braga, B., Tundisi, J. (Orgs.). Águas doces no Brasil: capital ecológico, uso e conservação (3a ed.) São Paulo: Escrituras.

Rede Construção (2004). Consórcio das bacias hidrográficas dos rios Piracicaba, Capivari e Jundiaí (PCJ) obriga à redução do abastecimento da Região Metropolitana de São Paulo. Recuperado em 13 outubro, 2014, de http://www.redeconstrucao.com/consorcio-das-baciashidrograficas-dos-rios-piracicaba-capivari-e-jundiai-pcj-obriga-a-reducao-do-abastecimentoda-regiao-metropolitana-de-sao-paulo-2551

Rede Globo. (2014). Rap sobre economia de água. São Carlos: EPTV - TV Regional de São Carlos e Região. (1 minuto).

Ribeiro, B. (2014). Sugestões para elaboração de material informativo sobre escassez hídrica. Recuperado em 29 outubro, 2014 de backer.com@gmail.com

Silva, E. (2013, março 22). Desperdício de água chega a 35\% em Rio Claro. Jornal Cidade de Rio Claro. Recuperado em 22 outubro, 2014, de http://www.tratabrasil.org.br/desperdicio-deagua-chega-a-35-em-rio-claro-jornal-cidade-de-rio-claro-sp-dia-a-dia

Trindade, C. (2014). Sugestões para elaboração de material informativo sobre escassez hídrica. Recuperado em 07 novembro, 2014. de cautrindade@hotmail.com

Triviños, A. N. S. (1987). Introdução à pesquisa em ciências sociais: a pesquisa qualitativa em educação. São Paulo: Atlas.

Tundisi, J. G. (2003). Água no século 21: enfrentando a escassez. RIMA/IIE. 
Tundisi, J. G. et al. (2008). A bacia hidrográfica do Tietê/Jacaré: estudo de caso em pesquisa e gerenciamento. Estudos Avançados, 22(63), 159-172.

TV Claret. Com. (2014). Pesquisa sobre água (Período de 11 de maio a 30 setembro). Recuperado em $30 \quad$ setembro, 2014, de http://www.tvclaret.com/busca/?busca=\%E1gua\&bbusca.x=0\&bbusca.y=0\&bbusca=submit

Whirlpool. (2012). Relatório de Sustentabilidade 2012. Recuperado em 11 setembro, 2014, de http://www.whirlpool.com.br/Portals/11/files/RelatoriodeSustentabilidade.pdf

Yassuda, E. (1993). Gestão de recursos hídricos: fundamentos e aspectos institucionais. Revista Administração Pública, 27(2), 5-18.

YIN, R. K. (2003). Estudo de caso: planejamento e métodos (3a ed.). São Paulo: Bookman. 